\title{
Interpretation of radar-detected internal layer folding in West Antarctic ice streams
}

\author{
Robert W. Jacobel, Anthony M. Gades, David L. Gottschling, \\ Physics Department, St. Olaf College, Northfield, Minnesota 55057, U.S.A. \\ STEven M. Hodge, \\ Ice and Climate Project, U.S. Geological Survey, Tacoma, Washington 98416, U.S.A. \\ DAVID L. WRIGHT \\ Geophysics Branch, U.S. Geological Survey, Denver, Colorado 80225, U.S.A.
}

\begin{abstract}
Low-frequency surface-based radar-profiling experiments on Ice Streams B and C, West Antarctica, have yielded high-resolution images which depict folding of the internal layers that can aid in the interpretation of ice-stream dynamics. Unlike folding seen in most earlier radar studies of ice sheets, the present structures have no relationship to bedrock topography and show tilting of their axial fold planes in the flow direction. Rather than being standing waves created by topography or local variations in basal shear stress, the data show that these folds originate upstream of the region of streaming flow and are advected into the ice streams. The mechanism for producing folds is hypothesized to be changes in the basal boundary conditions as the ice makes the transition from inland ice to icestream flow. Migration of this transition zone headward can then cause folds in the internal layering to be propagated down the ice streams.
\end{abstract}

\section{INTRODUCTION}

Surface-based radar studies on Ice Streams B and C, West Antarctica, were conducted by a collaboration from the U.S. Geological Survey and St. Olaf College during the 1987-88 and 1988-89 field seasons. The primary purpose of these experiments was to examine in detail conditions at the bed of the ice streams and echo returns from structures within the ice which might give information about ice-stream dynamics, and ultimately help in determining the response of the West Antarctic ice sheet to climate change. In most cases, profiling was done in areas where other geophysical data were being acquired (seismic reflection, strain rates, airborne radar and highfrequency ground-based radar) so that comparisons could be made and interpretations based on a combination of different kinds of information. Altogether, over $750 \mathrm{~km}$ of surface profiles were completed in the 2 years resulting in nearly 2 gigabytes of digital data.

In the first year on Ice Stream B, a longitudinal line $36 \mathrm{~km}$ in length was profiled repeatedly near the Downstream B camp $\left(154^{\circ} 27^{\prime} \mathrm{W}, 83^{\circ} 51^{\prime} \mathrm{S}\right)$ using five transmitter frequencies ranging from 1 to $12 \mathrm{MHz}$ to enable spectral studies of the echo-energy content. Several short intersecting transverse profiles $3 \mathrm{~km}$ in length were also made. These, as well as the longitudinal profiles, coincided with the University of Wisconsin seismic lines and their $50 \mathrm{MHz}$ radar studies.

In the second season, data were acquired on Ice
Stream C near the Upstream C camp $\left(136^{\circ} 33^{\prime} \mathrm{W}\right.$, $\left.82^{\circ} 24^{\prime} \mathrm{S}\right)$. Two transverse profiles $95 \mathrm{~km}$ in length and $1 \mathrm{~km}$ apart were made which extended across the entire ice stream and into both marginal shear zones. Three longitudinal profiles $28 \mathrm{~km}$ long and $1 \mathrm{~km}$ apart were made along the Ohio State University strain grid near the camp, and a $5 \mathrm{~km}$ by $12 \mathrm{~km}$ sub-section of the strain grid was studied in detail with profiles in both longitudinal and transverse directions spaced approximately $1 \mathrm{~km}$ apart. All data on Ice Stream C were acquired at $4 \mathrm{MHz}$ center frequency of the short-pulse radar. Data densities at both sites were generally $2 \mathrm{~m}$ per recorded wave form with each record resulting from stacking (adding) 8192 individually digitized returns acquired in the $2 \mathrm{~m}$ interval. This amount of data stacking, together with design features of the radar system, gave a system sensitivity of more than $180 \mathrm{~dB}$ (Wright and others, 1990), revealing dramatic detail in the structure of internal layers in the ice. Figures in this paper utilize varying degrees of compression to fit profiles on a single page and so do not depict the full resolution and details actually present in the data.

The radar system used had been discussed by Wright and others $(1989,1990)$ and the field program and preliminary results have been described by Hodge and others (1989) and Jacobel and others (1990a, b). Lowfrequency ground-based radar was used because of the relatively large signal returns from internal structures and because it is complimentary to other airborne and 
ground-based radar programs which have been ongoing in this area (Moore and others, 1989; Retzlaff and others, 1993).

Data were originally acquired on $\frac{1}{2}$ in magnetic tapes and later transcribed to optical cartridges for more efficient access to the files. Analysis of the data has been carried out at St. Olaf College using a combination of DOS-based personal computers and UNIX work stations, the latter primarily to accomplish some of the processing tasks. Profile results are depicted in color plots of surfacetravel distance versus time (depth) with echo strength represented by a color-amplitude scale. The color palette has been chosen to contrast colors with high and low "value" (hue-saturation-value scale) to depict phase information in the returned wavelet. Thus, a sinusoid (plus to minus wavelet) shows up as a dark-light color pair. Reproduction of this color palette in the black-andwhite figures presented here preserves most of the phase information, but the amplitude scale is more difficult to see.

The presence of hyperbolic reflectors in some of the plots indicates that point-like objects are being imaged by the radar at different angles. In a similar way, it is possible for the finite beam width of the radar to produce distortions in the appearance of steeply dipping reflectors (Yilmaz, 1987). In the case of the ice streams, bedrock topography is not an issue since it is essentially flat, but possible distortions of the shape of internal layering need to be explored. We have adapted two-dimensional seismic migration techniques for this purpose and applied them to the data. In no case have we found that migration changes the shape of the bed in any of the profiles, or the amplitude or slope of folds in the internal layers. While this could not have been assumed a priori, it is not surprising since the slopes involved are typically less than a few degrees, and are nowhere greater than $16^{\circ}$ (though they appear more dramatic in figures with vertical exaggeration). Radar profiles shown throughout this paper are the unmigrated sections which generally have greater clarity. Echo-arrival time is the vertical axis, but an approximate depth scale is indicated on the right

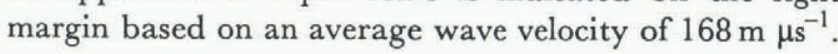

\section{ICE STREAM G DATA}

Figure 1 shows a plan map of radar profiles done near the Up C camp and their relationship to the Ohio State University strain grid which is oriented approximately along the flow direction (Whillans and Van der Veen, 1984). Profiles F, G and $\mathrm{H}$ coincide with lines of the strain grid, and were augmented along a $12 \mathrm{~km}$ section on each side with profiles $\mathrm{HH}$ and $\mathrm{FF}$, separated by approximately $1 \mathrm{~km}$. Also, $5 \mathrm{~km}$ long cross-profiles were done from $\mathrm{km} 19$ to $\mathrm{km} 31$ on the strain grid at approximately $1 \mathrm{~km}$ intervals. Parts of the two $95 \mathrm{~km}$ long transverse profiles, lines D and E, are also shown in the figure. This arrangement provided a radar grid at approximately $1 \mathrm{~km}$ spacing, coinciding with the central part of the strain net and extending laterally beyond it by an additional kilometer in each direction.

Figure 2 shows profile results from the $12 \mathrm{~km}$ long $\mathrm{HH}$ line oriented approximately along the flow direction,

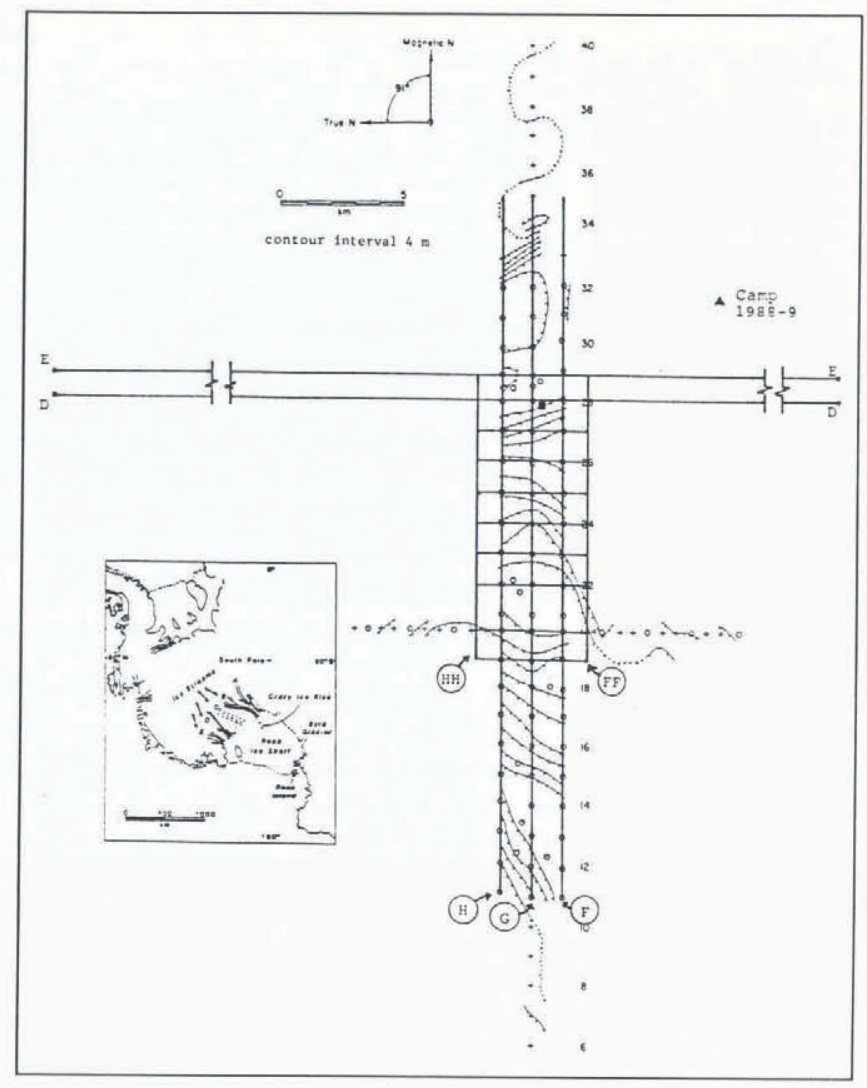

Fig. 1. Map of radar-profile lines in the vicinity of the upstream camp on Ice Stream C. Contour lines show surface topography along the Ohio State University strain grid (adapted from Whillans and Van der Veen, 1984).

which is from right to left in the figure. Surface slopes in this part of the ice stream are about 0.005 and topography has little relief, so the ice thickness depicted by the bed echo corresponds very closely to bedrock topography. In addition to the bed echoes, the profile shows weaker returns from internal layers within the ice, some of which are quite prominent such as the one at a depth of approximately $725 \mathrm{~m}$. Of particular interest is the folding of these layers which bears no simple relationship to the topography beneath. Also, these folds decrease in amplitude from the bed toward the surface. Careful examination of the profile reveals a tilting of the axial fold plane in the direction of flow, a point we shall return to in the discussion.

Figure 3 shows results from the $\mathrm{H}$ line profile along a $12 \mathrm{~km}$ segment directly adjacent to the $\mathrm{HH}$ line in Figure 2. Bedrock similarities are apparent as might be expected for the two sections separated by only $1 \mathrm{~km}$. What is more interesting is that a number of the more prominent internal layers can be traced unambiguously from one profile to the next as can be seen clearly in the layer at approximately $725 \mathrm{~m}$ in both. We have identified this layer in profiles throughout the grid in both longitudinal and transverse directions, and this has enabled us to produce a contour map and mesh-surface depiction of this layer for the grid region. A similar map has also been made for ice thickness (essentially equivalent to bed topography). These are shown in Figures 4 and 5, respectively. While the large-scale features are broadly similar, the details of the layer surface bear no simple relationship to the bedrock topography below. The 


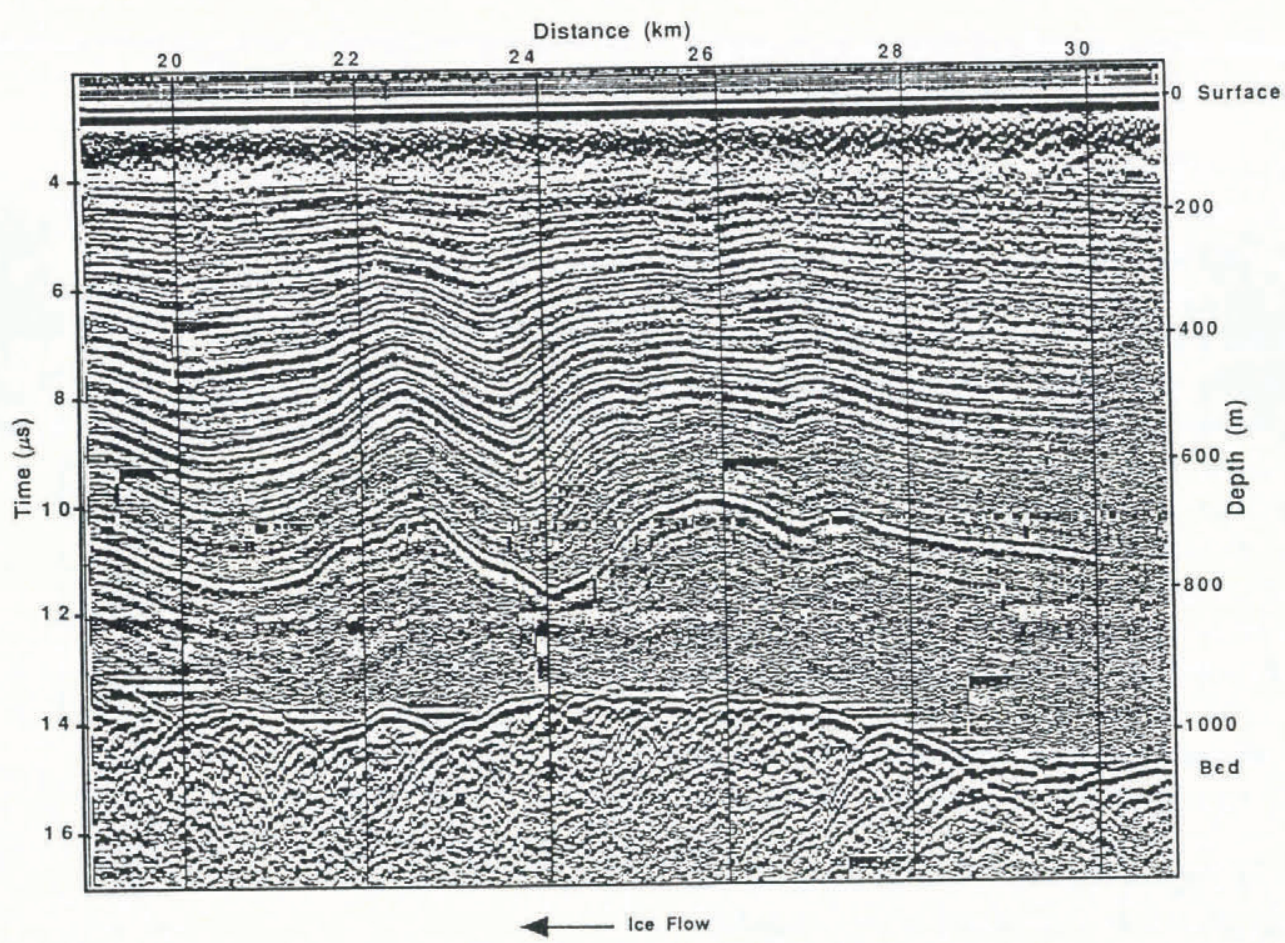

Fig. 2. Radar-profile image acquired along the HH line. Vertical exaggeration is approximately $5.5: 1$. Average surface slope in the grid region is 0.005 with little topographic relief, so ice thickness corresponds closely to bed topography. Note that the internal layer folding does not correspond to bedrock topography, and also the tilting of fold axial planes in the flow direction.

rounded ridge in the bed which rises approximately $170 \mathrm{~m}$ in the flow direction controls the general shape of the internal layer, but the similarity ends there. Correspondence of long wavelength features is not surprising since the ice must flow over the bed, but the lack of similarity on other scales is not anticipated. Also of interest is the fact that the folding pattern in the internal layering does not correspond to what would be expected from the strain-grid data (Whillans and Van der Veen, 1993). We shall return to both of these points in the discussion.

Figure 6 shows a transverse profile from a part of the

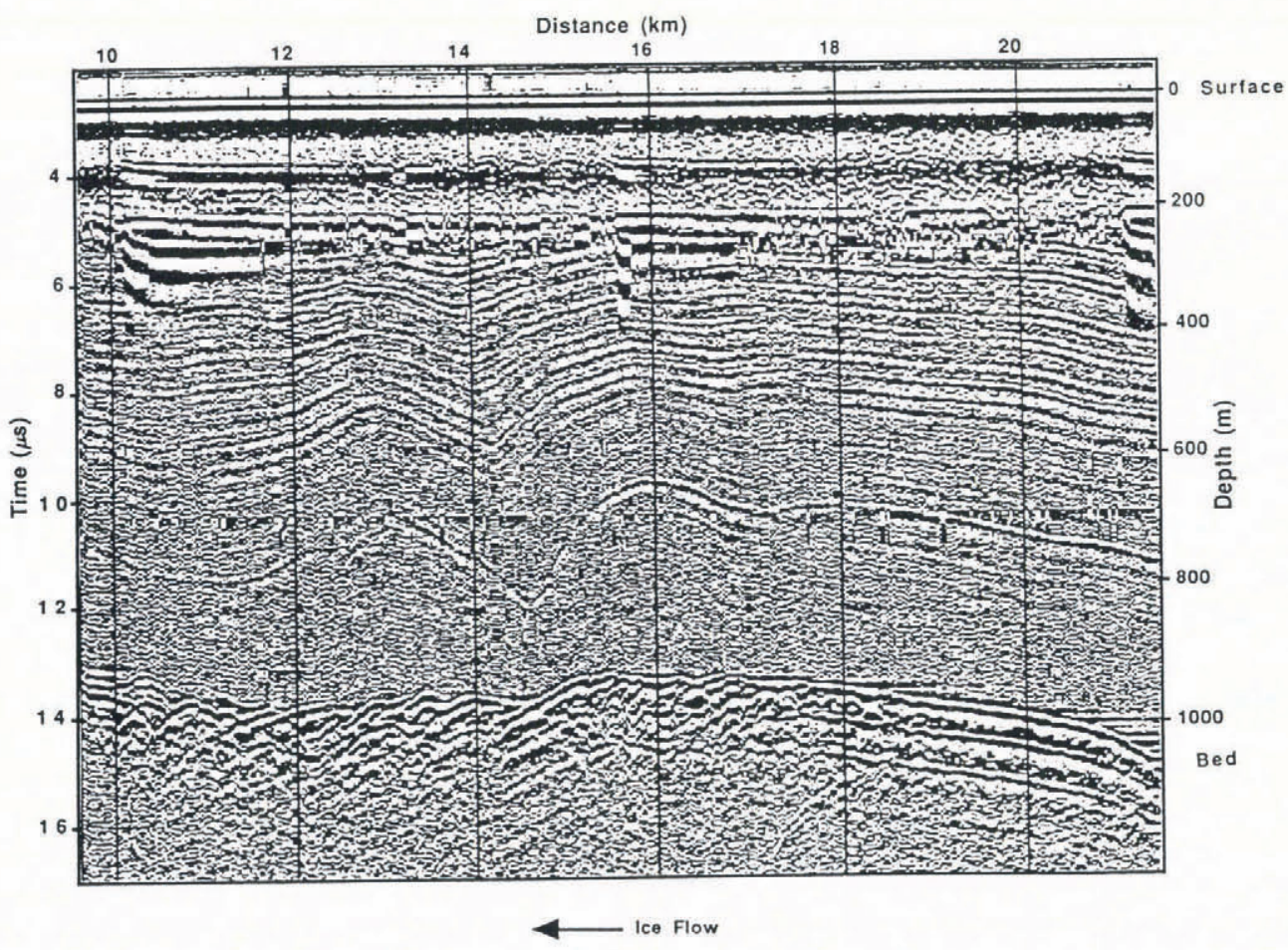

Fig. 3. Radar-profile image acquired along a section of the $H$ line parallel to Figure 2 and separated by $1 \mathrm{~km}$. Note the general correspondence of the bedrock topography with that in Figure 2, and the same prominent internal layer at approximately $725 \mathrm{~m}$. 


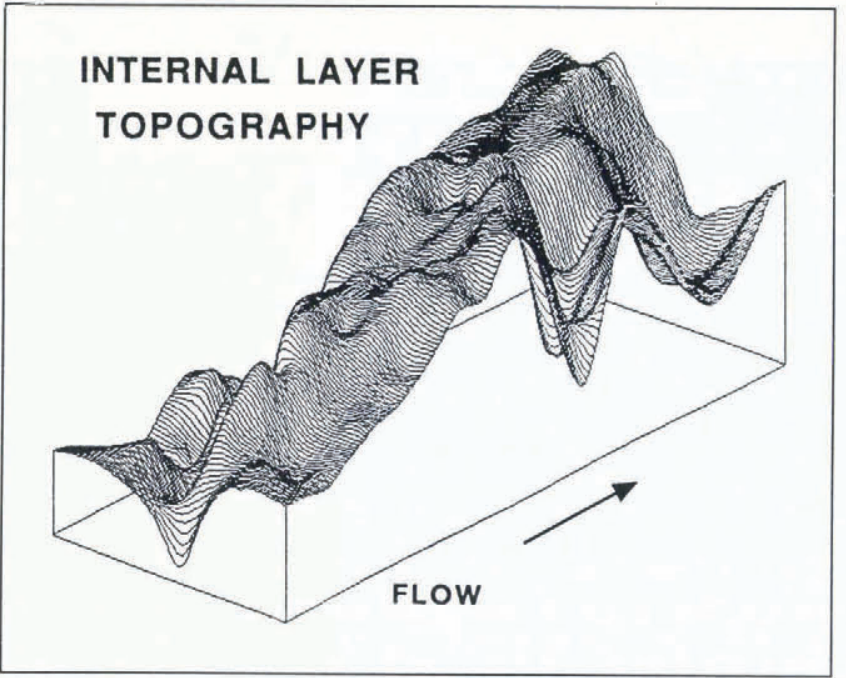

Fig. 4. Mesh-surface depiction of the prominent internal layer at approximately $725 \mathrm{~m}$ beneath the augmented strain grid $(5 \mathrm{~km} \times 12 \mathrm{~km})$. Vertical relief corresponds to $223 \mathrm{~m}$. Note the lack of correspondence to the bed topography in Figure 5.

D line centered approximately over the strain grid at $\mathrm{km}-1$ in the figure coordinates. This profile shows that the strain grid is coincidentally positioned over a local rise in the bedrock, and that this is the highest bedrock (shallowest ice) across this section of the ice stream. Data from airborne radar studies done by the University of Wisconsin in this area show that this bedrock rise of $340 \mathrm{~m}$ is in fact the largest feature for several tens of kilometers in any direction (Retzlaff, 1991; Retzlaff and others, 1993). While the internal layering is more difficult to examine in detail at this scale, it is clear that folding occurs in the transverse direction as well. What is even more interesting is that the wavelength scale of the folds seems to decrease by a factor of two or more from the region over the bedrock hill to the areas on either side.

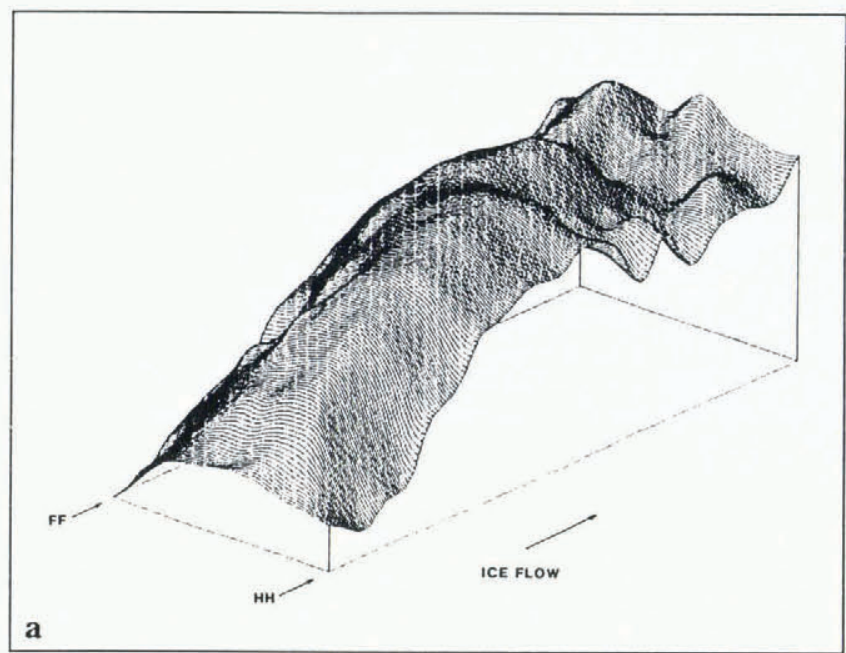

Fig. 5. Mesh-surface depiction (a) and contour map (b) of the region beneath the augmented strain grid. Contour interval is in meters, with total vertical relief corresponding to $180 \mathrm{~m}$. The surface depicted is essentially the same as bedrock topography since the ice-surface relief is negligible.
Similar folding in the direction transverse to flow has been described by Robin and Millar (1982) in a profile from the East Antarctic ice sheet which shows strong folding over a smooth bed. They pointed out that the folds are probably produced upstream by flow around obstacles in the bed and are retained under steady-flow conditions after the ice has passed the obstacles because of net transverse flow. A similar explanation probably applies in the present case though it is difficult to quantify how much of the transverse folding is produced upstream and how much is due to flow around the bedrock rise. Certainly, the shorter wavelength of the folds on either side of the bedrock rise is suggestive of greater lateral compression there. This seems to be supported by evidence from satellite imagery discussed next.

Additional understanding of what is occurring in terms of ice dynamics in the region of this rising bedrock ridge can be gained by considering the Landsat TM image of the area near the Up C camp (Fig. 7). This image was acquired on 24 January 1985 with the sun only a few degrees above the horizon. As such, it emphasizes continuous features with low topographic relief such as the streamlines surrounding the central region of more

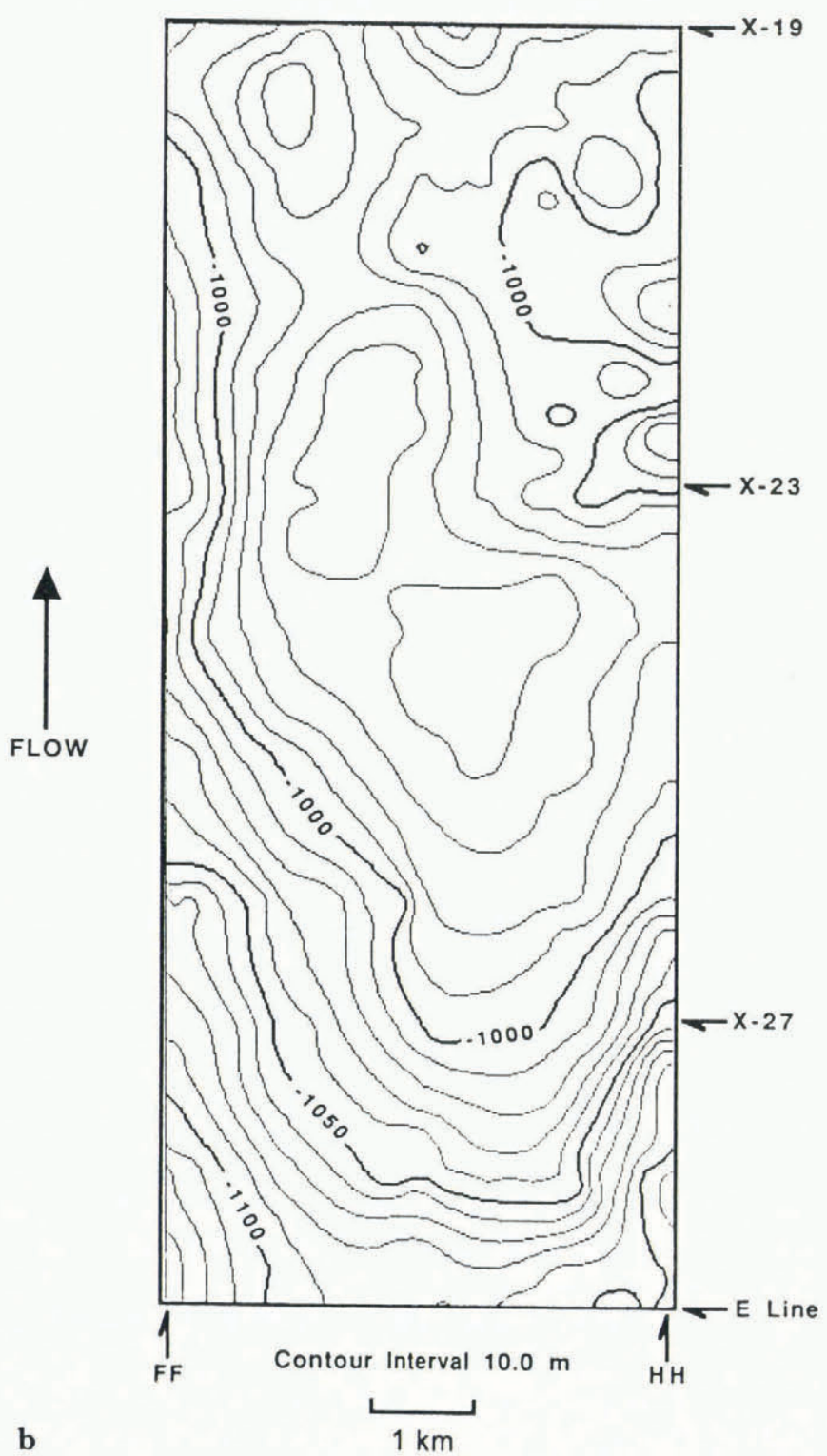




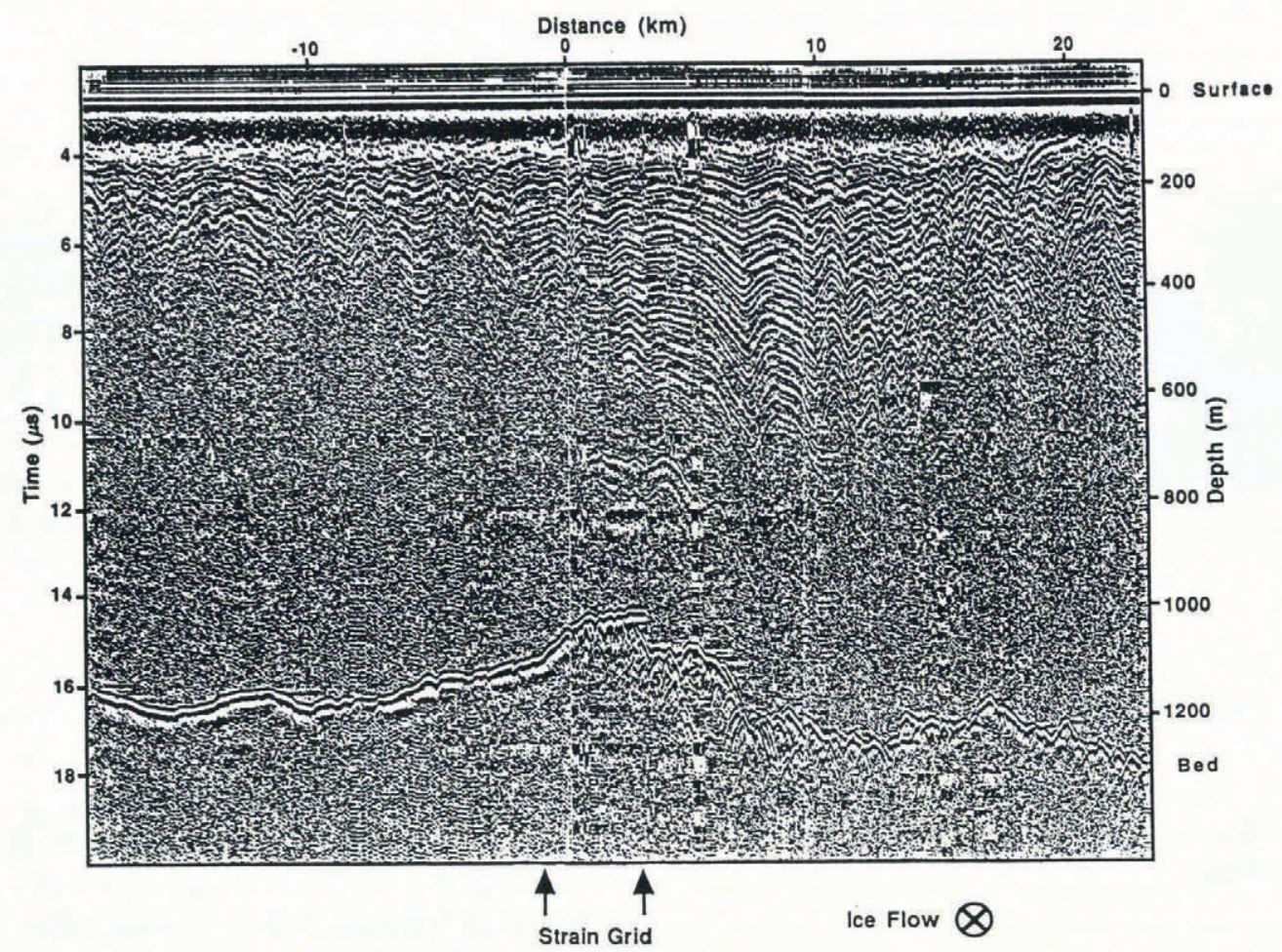

Fig. 6. Radar image from a transverse profile along the $D$ line. Vertical exaggeration is approximately $20: 1$, and arrows indicate the location of the strain grid. Note the decrease in wavelength of the folding by about a factor of 2 from the region over the topographic high to the areas on either side where ice velocities were once greater (see Fig. 7).

mottled topography. The information revealed by this image is remarkable because in the field these features are impossible to perceive visually and extremely difficult to locate by surveying techniques. This is because the contrast is the result of very small changes in the surface slope of a homogeneous surface. Registration of the image to surface features has been accomplished by matching pixel intensity patterns to surveyed topography (Casassa and Bindschadler, 1990).

The result of this registration shows that the central region of more mottled topography coincides with the location of the strain grid and radar survey, though the grid is not centered precisely within the region. Data from the strain grid show that velocities in this area are today less than $10 \mathrm{~m} \mathrm{a}^{-1}$, and other measurements made in the general area are comparable (Whillans and Van der Veen, 1993). Thus, the streamlines must be relicts of a flow regime which existed while Ice Stream $\mathrm{C}$ was still active. While the timing and sequence of events cannot be inferred from these data alone, it is apparent that the dominant ice-stream flow passed to either side of the bedrock rise.

Figure 8 shows a detail of one segment of the $\mathrm{HH}$ profile at a vertical exaggeration of about 1.9. This enhancement reveals areas of apparent fine structure in the internal layering. For example, the prominent layer at approximately $725 \mathrm{~m}$ shows a hyperbolic reflector just past $\mathrm{km} 22.5$ which is representative of structures we have seen in this and other profiles. One hypothesis of the origin of these point-like echoes is that they are due to old crevasses, formerly on the surface and filled with the same debris which creates the internal layers themselves. Occasionally, one of these closed crevasses lies across the path of the radar, and a "line source" is imaged as a point. Other orientations of the buried crevasses would be less likely to generate bright hyperbolas that are distinguishable from the layer itself.

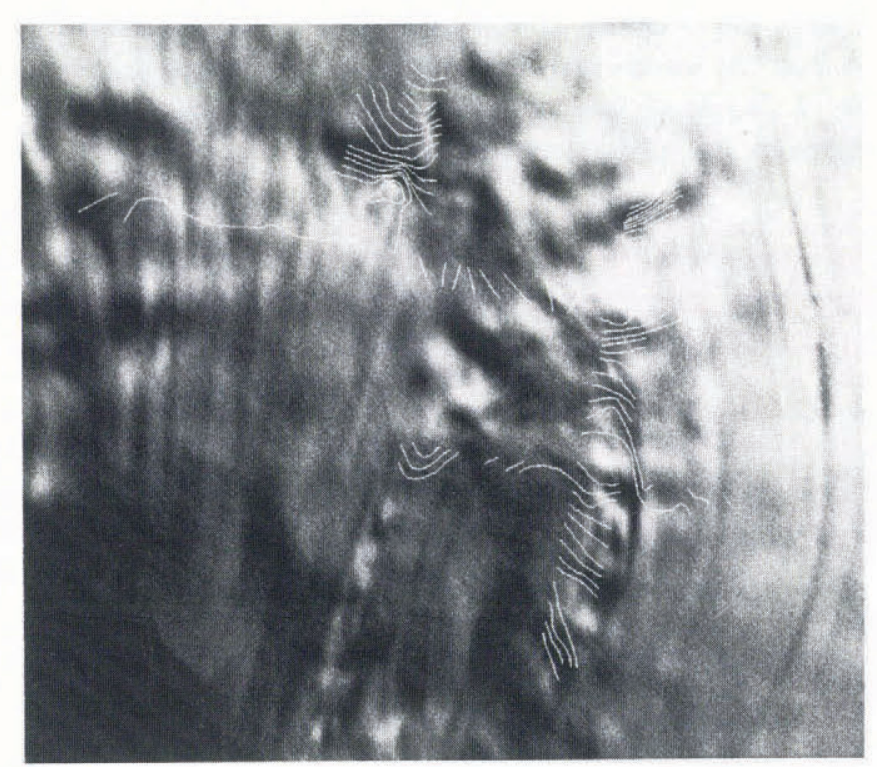

Fig. 7. Landsat TM image of the $U p C$ area $(40 \mathrm{~km} \times 35 \mathrm{~km})$ with strain grid (right of center) and surface contours $(4.0 \mathrm{~m}$ ) superposed (from paper in preparation by Casassa and others). Low-angle sun illumination emphasizes surface features with low topographic relief such as the areas of streaming flow surrounding the "island" with more mottled topography. The large bedrock rise in Figures 5 and 6 underlies the mottled terrain. 


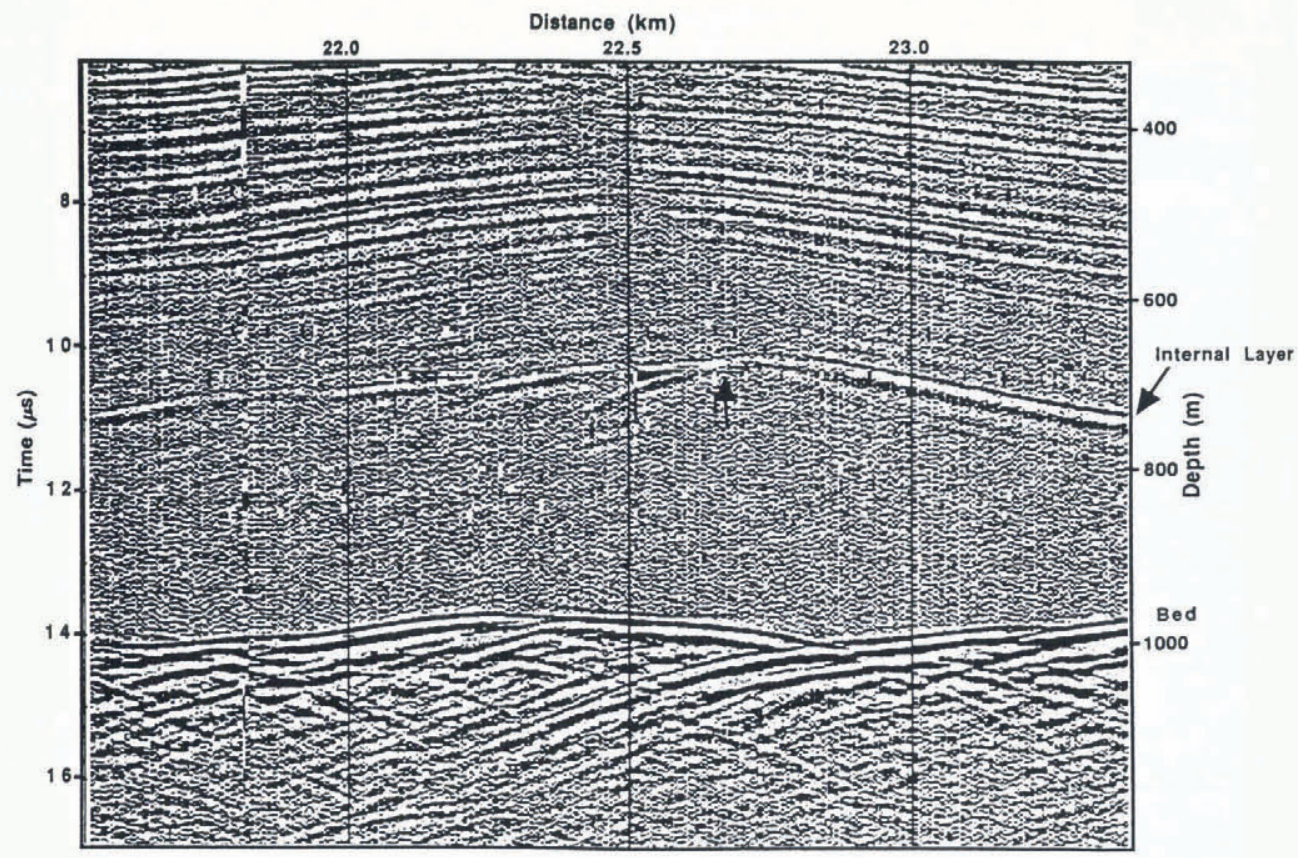

Fig. 8. Detail of one section of the $H H$ profile at 2.2:1 vertical exaggeration. The internal layer at approximately $725 \mathrm{~m}$ shows a hyperbolic point or line reflector (arrow) at km 22.7 in the figure coordinates, possibly produced by relict crevasses.

\section{ICE STREAM B DATA}

Figure 9 shows radar-profile results from a $12 \mathrm{~km}$ section of the $\mathrm{Z}$ line near the Downstream B camp on the ice plain of Ice Stream B. This region of the ice stream is characterized by very low surface slopes (on the order of 0.001 ) with essentially flat surface topography. The $36 \mathrm{~km}$ long line corresponds to the University of Wisconsin seismic reflection survey, and was the focus of most of our radar studies during the 1987-88 field season. This line runs approximately along the flow direction of the ice stream at this location, and was profiled at five different center frequencies of the transmitter in order to investigate the frequency dependence of the radar-echo sources. This profile was acquired at $4 \mathrm{MHz}$, while others were done at 1, 2, 8 and $12 \mathrm{MHz}$.

Unlike the topography beneath the upstream C location, the bed here has little relief. Bed echoes vary essentially monotonically from 762 to $790 \mathrm{~m}$ along the $36 \mathrm{~km}$ profile, assuming the wave speeds quoted above. Roughness features at the ice-bed interface produce the scattering hyperbolas which extend below the bed region in the figures. These may be the result of many small basal crevasses, or debris entrained in the ice. In principle, it should be possible to obtain information about the size distribution of these scattering sources by comparing the echoes obtained at the different transmitter frequencies. In practice, this is complicated by the fact that the radar-system sensitivity varies a great deal over the range of transmitted frequencies because the shorter antennas used at the higher frequencies do not couple as much energy to the ice. This means that it is harder to detect weaker echoes from point-like sources at higher frequencies. It is clear from our migration studies that many of the hyperbolic echoes come from off-nadir sources to either side of the profile line. As the transmitted frequency increases, it is still possible to get strong returns from the bed below, and even from the internal layers, but objects in the side lobes of the antenna pattern become harder to see. What we can say thus far is that scattering sources appear to become more numerous as the transmitted frequency goes from 1 to $4 \mathrm{MHz}$; thereafter it is difficult to tell because of the effects just described. For these and related reasons, we decided to use $4 \mathrm{MHz}$ as the center frequency for work on Ice Stream C. It is still our hope to extract further information about scattering sources with the help of computer-model studies of the basic physical processes involved.

While the bed beneath this active ice stream in this region is nearly horizontal, the internal layers, if anything, exhibit more folding than on Ice Stream C. The vertical exaggeration of approximately $8.7: 1$ in the figure overdramatizes this somewhat; slopes actually range up to $16^{\circ}$ above the horizontal in the areas profiled - about twice as much as on Ice Stream C. Quite clearly, the folding here too is not related to the underlying bedrock topography. As on Ice Stream C, these folds also show a progressive tilting of the axial plane in the ice-flow direction.

Figure 9 also shows the presence of an echo source below the more prominent continuous internal layers at approximately $\mathrm{km} 6$ in the figure coordinates. This series of hyperbolic-like echoes we believe is due to a large bottom crevasse which intersects the profile diagonally. This feature was also seen (though less prominently) in the University of Wisconsin $60 \mathrm{MHz}$ ground-based profiling and has been described by Novick and Bentley (1990).

Figure 10 shows approximately the same profile section at $2 \mathrm{MHz}$ center frequency of the transmitter. While signal strength is increased due to better coupling of the longer antenna with the ice, resolution (in the sense 

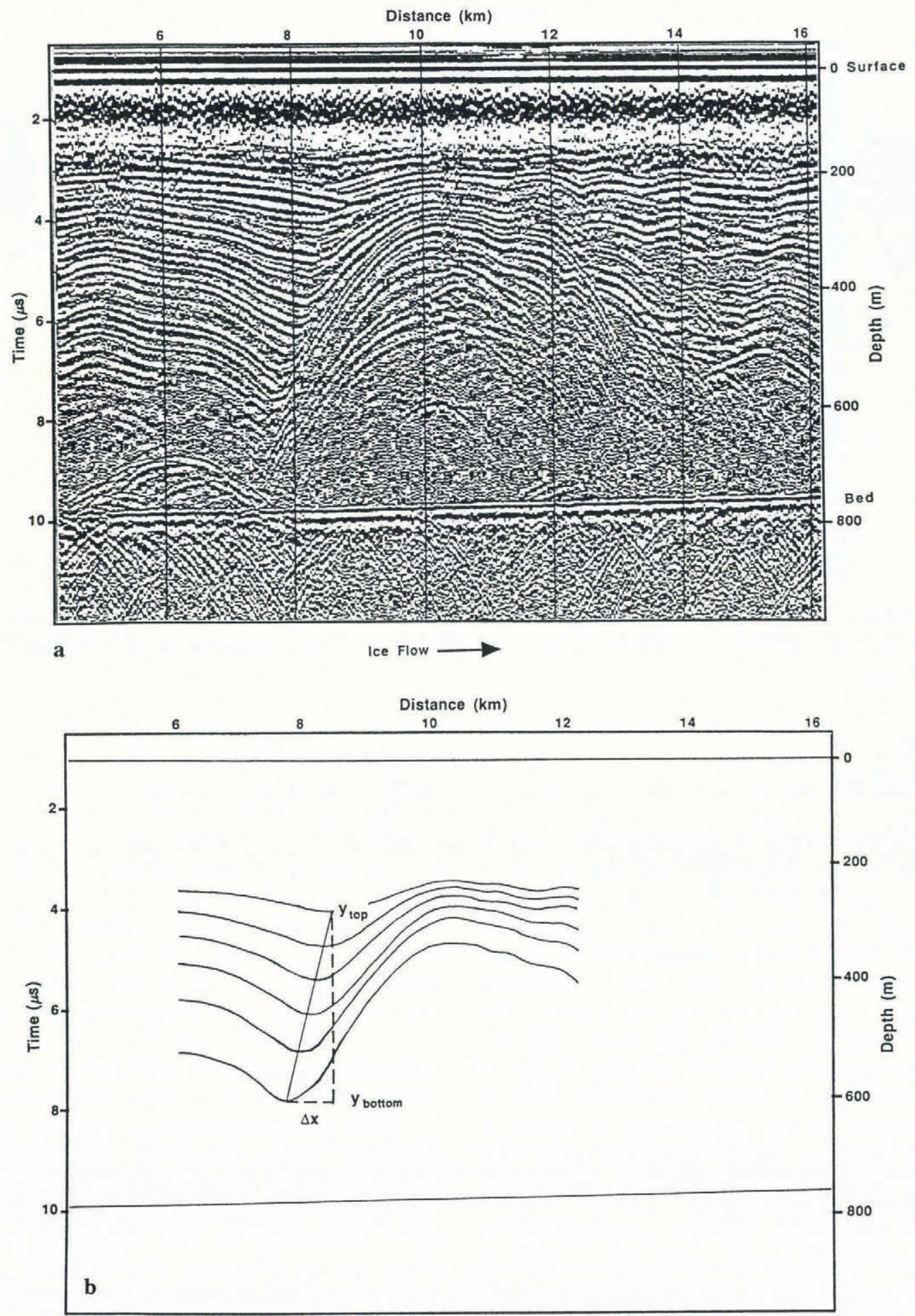

Fig. 9. a. Radar-profile image acquired at $4 \mathrm{MHz}$ center frequency of the transmitter from the Downstream $B$ area along the longitudinal Z line. Vertical exaggeration is $8.7: 1$. Surface slope is approximately 0.001 with essentially no topographic relief. Strong folding of the internal layering has no correspondence with the flat-bed topography, and foldaxial planes are tilted in the flow direction. Note the hyperbolic-like echoes near $\mathrm{km} 6$ in the figure coordinates, thought to have been produced by a large crevasse at the bed running diagonal to the profile. $b$. Tracing of the internal layer folding of Figure 9a showing the tilting of the fold-axial planes in the flow direction. Accumulated longitudinal shear strain is indicated by the tilt and may be used with the flow law to calculate the approximate time since the folds were produced.

of ability to distinguish echoes closely spaced in time) is sacrificed. Thus there appear to be only about half as many internal layers as in Figure 9. Analysis of the data acquired at all frequencies shows this approximately linear relationship between apparent separation of the internal layers and input center frequency. From this we can say it is likely that many more internal layers exist than we are actually resolving in these data. The wavelengths of the radar impulse in ice range from approximately 14 to $160 \mathrm{~m}$, and echo sources spaced more closely than a wavelength cannot be resolved. Nevertheless, it is important to point out that the layers 


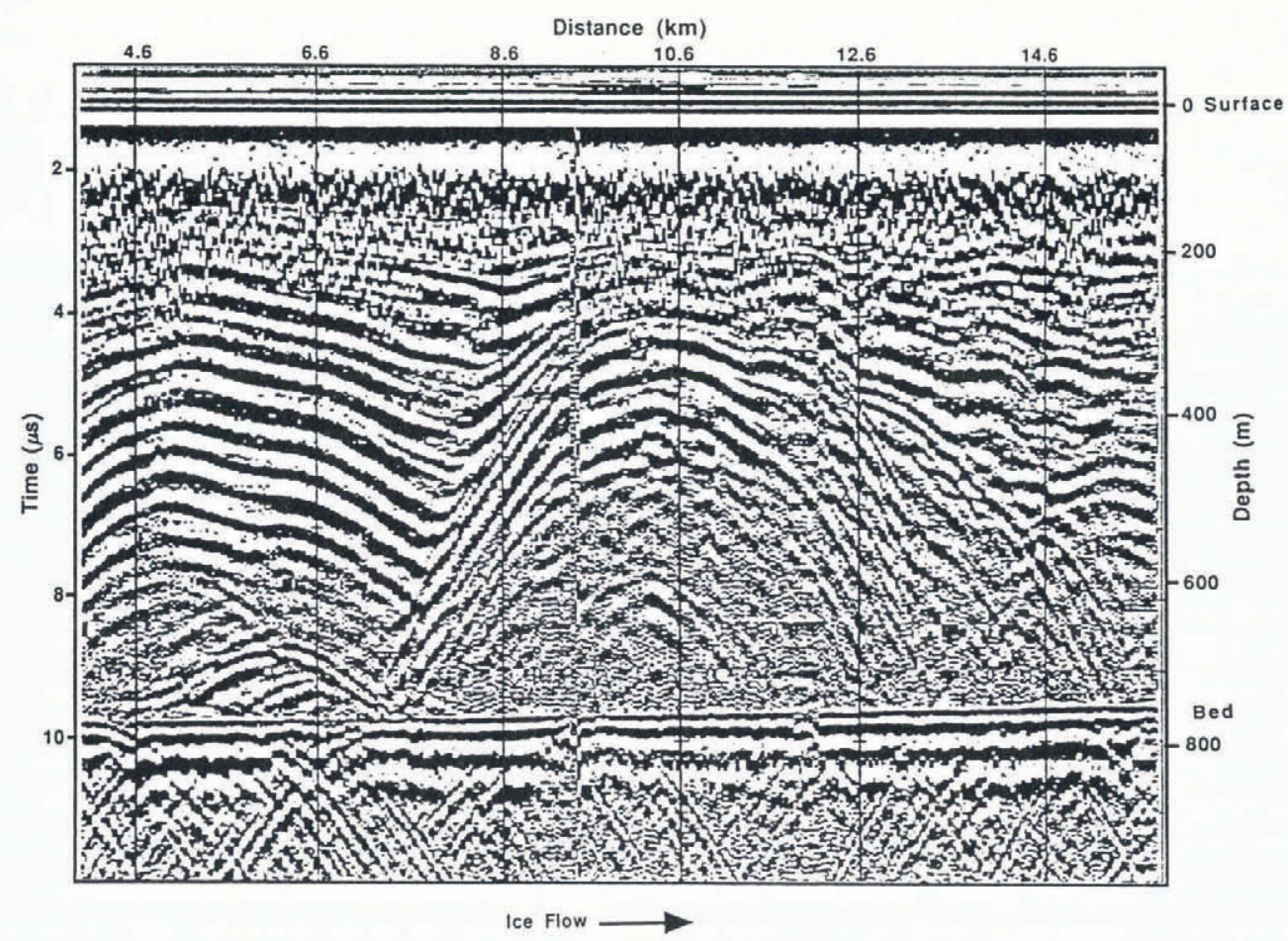

Fig. 10. Radar-profile image acquired at $2 \mathrm{MHz}$ along the same line as in Figure 9. The number of apparent internal layers is approximately half of those seen at $4 \mathrm{MHz}$ in Figure 9.

depicted represent real changes in the dielectric properties of the medium, and that their folding and tilting correspond to actual deformation of the ice.

\section{DISCUSSION}

The ability to depict strain within ice masses by imaging convolutions in the internal layering raises intriguing possibilities for understanding ice dynamics. The question is how best to use these data to make interpretations. Internal layering observed from airborne radar sounding has been studied by Whillans and Johnsen (1983) near Byrd Station, West Antarctica, in the region of more normal ice flow which feeds the ice streams. Using simple modeling techniques, they showed that folding in the internal layering could be related directly to bedrock topography or to spatial variations in basal shear stress. Similar results relating folding to bedrock topography were obtained by Budd (1970). The essential result of all this work is that spatially varying, but otherwise steadystate, basal boundary conditions produce convolutions in the internal layering which remain fixed with respect to the bed, that is, standing waves in the internal layers. Furthermore, while the amplitude of the folds in the internal layers decrease from the bed toward the surface, the phase relationship of crests and troughs remains constant. The fold axial planes do not tilt as folds are formed.

These model features are in contrast to the situation we have found on both ice streams where quite clearly the folding is not being generated locally by bed topography. The second possibility, that folding is the result of local variations in basal shear stress, is also highly unlikely. Evidence against this is strongest in the case of the downstream B data where the ice is barely grounded and has lost mechanical contact with the bed. Bindschadler and others (1987) have calculated basal shear stresses in this region from a force-balance study and reported very low values of $0.28 \pm 0.69 \mathrm{kPa}$. Seismic studies done on the ice plain (Blankenship and others, 1988; Rooney, 1988) show that it is underlain by a weak layer of wet deformable till which could not support the gradients in basal shear stress needed to produce the folding seen. At the upstream $\mathrm{C}$ location, data from the strain grid have been used in a force-balance study to calculate stresses at the bed (Whillans and Van der Veen, 1993). Again, patterns in the internal layer folding do not correspond to what would be expected from the variations in basal shear stress. We conclude therefore that the folding must be generated upstream.

The above discussion is somewhat simplified in that the model results which produce standing waves apply strictly only to two-dimensional flow. We have noted previously that folding in the direction transverse to flow probably results from net lateral ice movement which retains fold features downstream of obstacles. However, this cannot occur along the flow direction under steadystate conditions, and some additional mechanism is needed to propagate the folds downstream.

Propagating folds in internal layering have been studied in a numerical model by Hudleston (1976) who, together with Hooke, observed these effects visually in cross-sections near the terminus reigon of Barnes Ice Cap (Hooke and Hudleston, 1978). This model uses a simple bedrock bump, together with a step-function perturbation in the mass balance, to propagate folds downstream. Hudleston (personal communication) has pointed out that similar behavior can result from any timedependent change in the flow-regime parameters. This idea holds interesting possibilities for interpreting radar data from the ice streams. 
Setting aside for the moment the question of the mechanism for producing the folds, let us consider the tilting of these fold axial planes noted earlier. In all the profiles we have studied, fold axial planes are found to be tilted in the flow direction. Since the axial planes cannot be tilted as they are formed, the tilting provides a measure of the accumulated longitudinal shear strain since the time they were produced. We have calculated this shear strain for a number of fold features on both ice streams by measuring the tilt of fold crests and troughs. An example of this is shown in Figure 9b, a tracing of a part of the internal layer folds in Figure 9a. The shear strains calculated in this way from different fold features are consistent within each ice stream, and show an average of about $2 \frac{1}{2}$ times as much accumulated shear strain on Ice Stream B as on Ice Stream C.

These values may be used in a simple calculation to show how long it has taken to accumulate this shear strain, and thus to make a rough estimate of how long ago the folds were initiated (personal communication from $\mathbf{N}$. Humphrey, 1990). Assuming that the ice flow is laminar and two-dimensional, a simple integration of the flow law over the relevant ice thickness will give velocity differences between the ice at top and bottom of any column. That is:

$$
V_{\text {Top }}-V_{\text {Bottom }}=\frac{2 A}{n+1}(\rho g \sin \alpha)^{n}\left(Y_{\text {Top }}^{n+1}-Y_{\text {Bottom }}^{n+1}\right)
$$

where $A$ and $n$ are the flow-law parameters, $\alpha$ is the surface slope and $Y$ is the depth to any given layer. This velocity difference acting over time $\Delta T$ will produce the horizontal offset of the layer folds nearer the surface relative to those near the bottom, $\Delta X$.

$$
\Delta X=\frac{2 A}{n+1}(\rho g \sin \alpha)^{n}\left(Y_{\text {Top }}^{n+1}-Y_{\text {Bottom }}^{n+1}\right) \Delta T .
$$

Using an average surface slope of 0.005 , the flow-law parameters $n=3$ and $A=3 \times 10^{-16}$, and values of $\Delta X$ and $Y$ from the data, the equation may be solved for the time $\Delta T$ since the folds were formed. Values obtained in this way are on the order of several thousand years.

While these ages should not be considered to be precise, the order of magnitude is instructive. It suggests that the processes responsible for generating these folds occur many kilometers upstream, perhaps in the zone of transition from more normal ice-sheet flow to icestreaming flow. The calculation is dominated by the low surface slope of the ice streams, and thus the low driving stresses which require the large amounts of time needed to produce the observed shear strains. That the origin of the folds should be above the ice streams is an idea also supported by experimental work. Evidence is accumulating from drilling experiments that the ice streams have generally very low internal deformation and low basal shear stress (Engelhardt and others, $1990 a, b)$. These values would seem to preclude generation, within the ice streams, of the large-scale folding that is seen in the radar records.

Returning now to the mechanism of generating the folds, we are still left with the fact that no amount of folding produced by topography or steady-state drag elements at the bed can be advected into the ice streams. Arguing from the work of Hudleston, what seems to be required is a time-varying basal boundary condition such that folds can be produced in one stress regime, and then advected into the ice streams in another where they can then propagate essentially undisturbed, except for the observed tilting in the flow direction. This kind of behavior might be produced, for example, by a transition region which is unstable, and itself migrates upstream with time. If the ice streams are growing in length headward as has been proposed (Whillans and Bolzan, 1987; Shabtaie and others, 1988), waves in the internal layering may be shed downstream by just such a mechanism. We are currently pursuing modeling studies of these kinds of time-dependent phenomena to see if we can produce propagating folds in the internal layering and better understand the behavior.

\section{GONGLUSION}

Surface-based impulse-radar studies have been used to make high-resolution surveys of two of the ice streams which reveal details of the bedrock topography and internal layering not seen before in any ice mass. The high signal to noise ratio needed to detect and resolve these layers is the result of the receiver design and transmitted frequencies, the large amount of stacking and the high data density (wave forms acquired per meter). As a result, this low-frequency study has proven to be a valuable complement to higher-frequency airborne work which gives greater geographic coverage at lower signal to noise ratio and less resolution.

The patterns of folding in the internal layers appear to contain valuable information about ice-stream dynamics not available by any other means. Our interpretation of the information is tentative but is aided by, and is consistent with, other geophysical studies being conducted on the ice streams. Folding appears to be initiated well upstream of all areas studied, probably at the transition zone to ice-stream flow. Constraints on the mechanism leading to the generation of these folds require time-dependent changes in basal shear stresses such as might be produced by a headward migrating ice stream. This suggests several possibilities for future low-frequency surveys at locations near the onset of streaming flow.

\section{ACKNOWLEDGEMENTS}

The authors wish to acknowledge N. Humphrey for valuable discussions about flow-law calculations applied to the observed shear strains, and processes we hypothesize may be occurring at the bed. Also we thank P. Hudleston and R. Hooke for discussions about internal layer folding and their model results. Not least, we thank K. Nelson and S. Anderson, St. Olaf College physics students, for essential work on the data processing and analysis. Parts of this work were done while one of us (R.W.J.) was on sabbatical leave at the Institute for Arctic and Alpine Research (INSTAAR), University of Colorado, Boulder, Colorado. We thank M. Meier, T. Pfeffer and the staff at INSTAAR for discussions and assistance. Funding came from the U.S. National Science Foundation Directorate for Polar Programs, grants DPP8517225 and DPP-8915850 to St. Olaf College, and DPP8518618 to the U.S. Geological Survey. 


\section{REFERENGES}

Bindschadler, R. A., S. N. Stephenson, D. R. MacAyeal and S. Shabtaie. 1987. Ice dynamics at the mouth of Ice Stream B, Antarctica. 7 . Geophys. Res., 92(B9), 8885-8894.

Blankenship, D. D., S. T. Rooney, R. B. Alley and C. R. Bentley. 1989. Seismic evidence for a thin basal layer at a second location on Ice Stream B, Antarctica. [Abstract.] Ann. Glaciol., 12, 200.

Budd, W. F. 1970. Ice flow over bedrock perturbations. F. Glaciol., 9(55), $29-48$.

Engelhardt, H., N. Humphrey and B. Kamb. 1990a. Borehole geophysical observations on Ice Stream B, Antarctica. [Abstract.] EOS, 71 (43), 1302.

Engelhardt, H., N. Humphrey, B. Kamb and M. Fahnestock. 1990b. Physical conditions at the base of a fast moving Antarctic ice stream. Science, 248(4951), 57-59.

Hodge, S. M., R. W. Jacobel and D. L. Wright. 1989. Low-frequency ice radar studies on ice streams B and C, West Antarctica. Antarct. $\mathcal{F}$. U.S., 24(5), 79-81.

Hooke, R. LeB. and P.J. Hudleston. 1978. Origin of foliation in glaciers. 7. Glaciol., 20(83), 285-299.

Hudleston, P. 1976. Recumbent folding in the base of the Barnes Ice Cap, Baffin Island, Northwest Territories, Canada. Geol. Soc. Am. Bull., 87(12), 1684-1692.

Jacobel, R. W., S. M. Hodge and D. L. Wright. 1990a. High resolution radar studies of internal layers and bedrock topography on ice streams B and C, West Antarctica. [Abstract.] EOS, 71(43), 1303.

Jacobel, R. W., S. M. Hodge and D.L. Wright. 1990b. Studies of internal layering and bedrock topography on Ice Stream C, West Antarctica. Antarct. F. U.S., 25(5), 82-85.

Moore, R. K., C. H. Davis, W. Xin and R. H. Dean. 1989. Radar depth sounding near Upstream B camp-December, 1988. Antarct. F. U.S., 24(5), 85-86.

Novick, A. N. and C. R. Bentley. 1990. A longitudinal bottom crevasse on the ice plain of Ice Stream B, Antarctica. [Abstract.] EOS, 71(43), 1303.
Retzlaff, R. 1991. Airborne radar studies: ice streams A, B and C, West Antarctica. (M.S. thesis, University of Wisconsin.)

Retzlaff, R., N. Lord and C. R. Bentley. 1993. Airborne-radar studies: Ice Streams A, B and C, West Antarctica. F. Glaciol., 39(133), 495-506.

Robin, G.deQ. and D.H.M. Millar. 1982. Flow of ice sheets in the vicinity of sub-glacial peaks. Ann. Glaciol., 3, 290-294.

Rooney, S. T. 1988. Subglacial geology of Ice Stream B, Antarctica. (Ph.D. thesis, University of Wisconsin.)

Shabtaie, S., G. R. Bentley, R.A. Bindschadler and D. R. MacAyeal. 1988. Mass-balance studies of ice streams A, B and C, West Antarctica, and possible surging behavior of Ice Stream B. Ann. Glaciol., 11, 137-149.

Whillans, I. M. 1984. Ice stream dynamics. Antarct. F. U.S., 19(5), 51-53.

Whillans, I. M. and J. Bolzan. 1987. Velocity of ice streams B and C, Antarctica. 7. Geophys. Res., 92(B9), 8895-8902.

Whillans, I. M. and S.J. Johnsen. 1983. Longitudinal variations in glacial flow: theory and test using data from the Byrd Station strain network, Antarctica. 7. Glaciol., 29(101), 78-97.

Whillans, I.M. and C.J. van der Veen. 1993. New and improved determinations of velocity of Ice Streams B and C, Antarctica. f. G rciol., 39(133), 483-490.

Wright D. L., S. M. Hodge and J. A. Bradley. 1989. Use of a new highspet 1 digital data acquisition system for airborne ice-sounding. IEE E Trans. Geosci. Remote Sensing, 27(5), 561-567.

Wright, D. L., S. M. Hodge, J.A. Bradley, T. P. Grover and R.W. Jac'obel. 1990. A digital low-frequency, surface-profiling ice-radar sys3:m. J. Glaciol., 36(122), 112-121.

Yilmaz, O. 1987. Seismic data processing. Tulsa, OK, Society of Exploration Geophysicists.

The accuracy of references in the text and in this list is the responsibility of the authors, to whom queries should be addressed. 